From the Margins 



\section{From the Margins}

Historical Anthropology and Its Futures

Edited by Brian Keith Axel

Duke University Press Durham and London 2002 


\section{(C) 2002 Duke University Press}

All rights reserved

Printed in the United States of America on acid-free paper $\infty$

Typeset in Trump Mediaeval by Keystone Typesetting, Inc.

Permissions and Library of Congress Cataloging-in-Publication Data appear on the last printed page of this book. 